\title{
CORRIGENDA
}

Volume 16, pp. 230-237

\section{MYALGIC SYNDROME WITH CONSTITUTIONAL EFFECTS POLYMYALGIA RHEUMATICA}

\author{
BY \\ H. STUART BARBER \\ From the Rheumatism Unit, Withington Hospital, Manchester, and the Devonshire Royal Hospital, Buxton
}

Page 234, Column 2, Line 14, to read:

... The weight increased by $15 \mathrm{lb}$. and the E.S.R. fell to $40 \mathrm{~mm}$. $/ \mathrm{hr}$.

Page 236, Column 2, Last paragraph, to read:

The report of a discussion on the clinical aspects of polymyositis (Nattrass, 1956; Walton, 1956) suggests that this disease may be closely allied. Nevertheless, from the description, differences are apparent. Four clinical groups are identified, in all of which muscular weakness, wasting, and sometimes pain are so obtrusive that many cases are initially diagnosed as suffering from muscular dystrophy. One group contains cases of severe rheumatoid arthritis with secondary polymyositis and skin changes resembling exfoliative dermatitis, seborrhoeic dermatitis, lupus erythe- matosus, or scleroderma. Similarly to the condition now described, polymyositis, when not associated with malignant disease, either improves spontaneously, becomes arrested, or responds to steroid therapy. In none of the present series was there found a muscular weakness or atrophy suggestive of a muscular dystrophy nor did this develop during the course of the disease.

Page 237, Column 2, Paragraph 4, to read:

I am grateful to Professor J. H. Kellgren who kindly undertook to examine all the $X$-ray films of the cases and $\bar{C}$ confirmed that there was no evidence of rheumatoid arthritis and to Dr. J. Ball for the many sheep cell agglutination tests he has carried out on these cases. 